\title{
POTENCIALIDADES DO POLICIAMENTO COMUNITÁRIO NA REDUÇÃO DO USO DA FORÇA PELAS POLÍCIAS MILITARES
}

\section{ALAN FERNANDES}

Tenente Coronel da Polícia Militar do Estado de São Paulo, doutor em Administração Pública e Governo pela Escola de Administração de Empresas da FGV/SP, com estágio doutoral pelo King's College London.

País: Brasil Estado: São Paulo Cidade: São Paulo

Email de contato: alan@policiamilitar.sp.gov.br ORCID: https://orcid.org/0000-0003-1364-3868

\section{RESUMO}

Este trabalho discute a correlação entre o policiamento comunitário e o uso da força pelas polícias militares no Brasil. Estratégias policiais voltadas à aproximação comunitária têm sido uma fórmula acionada em todo o mundo, desde as décadas de 1970, e no Brasil, desde o início dos anos 1980. Tais políticas foram motivadas por uma promessa de ganhos quanto à prevenção do crime, aumento da confiança no trabalho policial, responsividade dos gestores policiais em relação à sociedade, transparência e mudança de modelos repressivos de enfrentamento ao crime para formas mais preventivas e construídas coletivamente. Tem, portanto, ao menos como pressuposto, que seu aprofundamento promoveria menores níveis de emprego da força pelos órgãos policiais. Contudo, a se julgar pelos mais de 20 anos das iniciais experiências no Brasil e pela permanência dos altos níveis de letalidade policial, vislumbra-se determinados limites dessa política pública. Com base nos registros das ocorrências atendidas pela Polícia Militar do Estado de São Paulo, a pesquisa recorreu a modelos quantitativos para analisar se, no período de maior impacto da implantação do policiamento comunitário naquele Estado (2004), eventuais reduções do uso da força se fizeram presentes nas unidades policiais (Companhias de Policiamento) abrangidas pelo projeto de implantação do modelo japonês Koban. Os resultados apontam que o policiamento comunitário pode impactar as práticas violentas da polícia militar a depender de outras variáveis implícitas a essa política pública, que, por vezes, são negligenciadas em prol do formalismo e da manutenção de lógicas institucionais.

Palavras-chave: Policiamento comunitário. Uso da força. Segurança pública. Letalidade policial. Políícas públicas.

\section{ABSTRACT THE POTENTIALS OF COMMUNITY POLICING IN THE REDUCTION OF USE-OF-FORCE LEVELS BY MILITARY POLICE FORCES}

This paper discusses a correlation between community policing and the use of force by military police in Brazil. Oriented-community police strategies have been a formula used worldwide, since the 1970s, and in Brazil, since the early 1980s. A promise of gains in crime prevention, increased confidence in the police work, responsiveness of police managers to society, transparency and shifting repressive models to fight crime toward more preventive and collectively constructed forms. Therefore, it is assumed that its deepening would 
promote lower levels of use of force by police agencies. However, according by the more than 20 years of the initial experiences in Brazil and the high levels of police lethality, certain limits of this public policy can be seen. Based on the records of events attended by the Military Police of the State of São Paulo, the research has used quantitative models to analyse whether, in the period of greatest impact of the implementation of community policing in that territory (2004), possible reductions in the use of force were made present in the police units (Policing Companies) covered by the project to implement the Japanese model Koban. The results show that community policing can affect the violent practices of the military police depending on other variables implicit in this public policy, that, sometimes, are neglected in favour of formalism and the maintenance of remaining institutional logics.

Keywords: Community policing. Use of force. Public security. Police lethality. Public policies.

Data de recebimento: 02/03/2020 - Data de aprovação: 24/11/2020

DOI: 10.31060/rbsp.2021.v15.n2.1269

\section{INTRODUÇÃO}

A discussão sobre o papel das polícias militares no Brasil transita entre duas posições bastante distantes: por um lado, uma forte demanda pelo aumento de sua capacidade de evitar os crimes e promover segurança; por outro lado, uma crítica de que tais corporações seriam incapazes de promover esses ganhos em direção à promoção de segurança pública com cidadania, em razão de sua própria estrutura burocrático-militar que não permitiria a participação social, insulando-se em suas próprias lógicas institucionais, marcadas por autoritarismo e preconceito, em especial contra populações situadas nos níveis mais inferiores na escala social. Essas duas posições marcam os debates no campo, ao menos desde a década de 1980, quando, naquela época, o aumento das taxas de crimes e o processo de reabertura política estabeleceram fronteiras de disputa discursiva, o que, de alguma forma, demarca os embates ainda hoje sobre o tema. Nesse panorama, o policiamento comunitário, trazido para o Brasil no início da década de 80, se mostrava como uma política de segurança pública que promoveria ganhos de legitimidade da polícia junto à opinião pública, pois tanto traria consigo novas formas de proporcionar segurança às pessoas como perfomaria práticas menos autoritárias.

Tendo sido implantado inicialmente nos Estados do Espírito Santo e do Rio de Janeiro nos primeiros anos da década de 1980, outras experiências se seguiram pelo Brasil, com o incentivo de governos estaduais e do governo federal, remanescendo, até os dias atuais, como um paradigma exitoso de reformas de oferta de polícia ostensiva. Cabe ressaltar que, recentemente, o governo federal editou a Portaria $n^{\circ} 43$, de dezembro de 2019 (BRASIL, 2019), que institui a Diretriz Nacional de Polícia Comunitária e cria um Sistema Nacional adstrito a essa temática, dando prova do afirmado acima.

Os projetos de polícia comunitária foram avaliados em diferentes aspectos, tendo recebido tanto avaliações positivas, ligadas sobretudo a melhores percepções de parcelas da população quanto ao serviço policial e à percepção de segurança, quanto avaliações negativas, que concluem pela resistência dos órgãos policiais, pela descontinuidade da política ou por representar, na verdade, um aprofundamento dos arbítrios policiais. Essas avaliações serão percorridas no presente trabalho. Todavia, as análises dos impactos do policiamento comunitário sobre o uso da força pelas polícias permanecem como uma agenda de pesquisa em aberto. Por essa razão, este artigo propõe analisar se a implantação do policiamento comunitário em São Paulo promoveu práticas menos violentas nas ocorrências em que policiais militares foram demandados a fazerem o uso de arma de fogo. Distancia-se, assim, dos trabalhos que analisam as 
dinâmicas das quantidades de mortes produzidas pela Polícia Militar do Estado de São Paulo, para analisar os eventos em que houve o uso da força letal, analisando seus resultados quanto às mortes, às lesões corporais ou à prisão de pessoas em ferimentos, tendo como hipótese explicativa que o policiamento comunitário teria a capacidade de promover mudanças nas práticas das polícias militares em favor de saídas menos repressivas e, portanto, menos violentas.

O artigo está estruturado em cinco partes. Na primeira, o policiamento comunitário é discutido sob os aspectos das motivações históricas e políticas, com especial ênfase à sua implantação no Estado de São Paulo com o estabelecimento da parceria com o Japão (2004). A segunda parte apresenta a metodologia utilizada para avaliar o impacto da sua implantação no uso da força das ocorrências atendidas pela PMESP nos anos 2003 a 2005. A terceira parte do trabalho discute os resultados encontrados e procura cotejálos em face das teorias sobre policiamento comunitário e violência policial. A quarta parte aprofunda as hipóteses explicativas diante das evidências de que, a priori, o policiamento comunitário não teria correlação com a diminuição do uso da força. A quinta parte trata dos problemas das políticas públicas da área da segurança no Brasil, marcada por poucas avaliações quanto às medidas adotadas por governos e gestores policiais, perpetuando pouca eficiência do Estado brasileiro nesse campo.

\section{DESENVOLVIMENTO}

Ineficiência no controle dos crimes e brutalidade policial estiveram nas origens da implantação do policiamento comunitário no mundo, razão pela qual ele remanesce como um paradigma de modelo de policiamento que seria mais consentâneo a uma proposta de reforma do papel das polícias em face de crises de legitimidade pelas quais passaram as corporações. Nos Estados Unidos, as revoltas desencadeadas pela morte de Rodney King em 1984 (MUNIZ; PAES-MACHADO, 2010; ROUSSEL, 2013) por policiais do Departamento de Polícia de Los Angeles foram as principais motivações para que fossem buscadas formas de oferta de polícia ostensiva que conjugassem maior proximidade com a população, de forma a permitir que a sociedade participasse das formulações das estratégias de enfrentamento ao crime e tornasse a corporação como um todo mais transparente quanto às suas práticas. Além de experiências nos Estados Unidos, outros países do hemisfério norte, como a Inglaterra (BOWLING; PARMAR; PHILLIPS, 2008) e o Canadá (MUNIZ; PAES-MACHADO, 2010), dentre outros, aproximaram suas práticas de modelos comunitários, igualmente impelidos pela tentativa de governos e polícias de verem aumentados seus níveis de confiança, em face do aumento de crimes e de queda da confiança no trabalho policial.

Essa demanda por maior legitimidade encontrou preocupação adicional na África do Sul pós-apartheid (STEINBERG, 2014) e na América Latina, ambos em uma tentativa política de adequar as corporações policiais aos modelos democráticos que se ergueram entre as décadas de 1980 e 1990, no sentido de torná-las responsivas à sociedade, bem como reconfigurar suas práticas cotidianas, marcadas por modelos essencialmente repressivos (COSTA, 2004; MUNIZ; PAES-MACHADO, 2010; RIBEIRO; MONTANDON, 2015). Além de déficits no controle do crime e baixos índices de legitimidade promovidos por formas violentas de atuação (KAHN, 2003; ROUSSEL, 2013), outros fatores promoveram a adoção de policiamento comunitário. Os processos de reforma do Estado segundo modelos neoliberais alavancaram perspectivas que configuraram essas novas formas de controle social, caracterizado por menores intervenções do Estado, maior presença da sociedade nas decisões estatais e maior accountabilityem relação aos agentes públicos (FRÜHLING, 2007; HEYER, 2016). Nesse ponto, o policiamento comunitário respondeu às demandas políticas mais amplas, introduzindo novas formas de governamentalidade caracterizadas por um controle social construído pela sociedade civil e pelo Estado. 
No Brasil, o policiamento comunitário constitui-se em uma política recorrente em diversos Estados do Brasil, como Piauí (SOUSA; FEIRREIRA, 2017), Paraíba (FRANÇA, 2019), Rio de Janeiro (COSTA, 2004; MUNIZ, 1999; RIBEIRO; MONTANDON, 2015), Minas Gerais (RIBEIRO; OLIVEIRA; DINIZ, 2016; UNIVERSIDADE FEDERAL DE MINAS GERAIS, 2009), Salvador (REIS, 2005) e São Paulo (CARDIA et al., 2003; KAHN, 2003; LOCHE, 2012; SILVA, 2006; SOUZA, 2019). Em São Paulo, a implantação do policiamento comunitário em 1997 foi impulsionada pelo caso conhecido como Favela Naval, em que policiais militares foram filmados agredindo e executando a tiros uma pessoa. Esse caso ganhou repercussão nacional, afetando sensivelmente os níveis de confiança da população em relação à corporação (BUENO, 2014; FRÜHLING, 2007; LOCHE, 2012; MANSO, 2012; SOUZA, 2019). Portanto, assim como em outras polícias, eventos graves de crise de imagem impulsionaram a introdução do policiamento comunitário.

Os contornos do que seja policiamento comunitário abrangem uma variedade de interpretações (RIBEIRO, 2014; RIBEIRO; MONTANDON, 2015; RIBEIRO; OLIVEIRA; DINIZ, 2016). A despeito disso, algumas características são tratadas na literatura como constitutivas do modelo, quais sejam: prevenção baseada na comunidade quanto ao mapeamento dos problemas e definição de prioridades; reorientação do patrulhamento, evitando-se o trabalho reativo e emergencial; emprego de metodologia de resolução de problemas e aumento da responsabilização sobre policiais e descentralização do comando (FERRAGl, 2013; LOCHE, 2012; MONTEIRO, 2005; RIBEIRO; MONTANDON, 2015). Para os fins deste trabalho, importa destacar que a proposição do policiamento comunitário se fundamentou na premissa de reconfigurar as lógicas das polícias militares, afastando as lógicas de enfrentamento ao inimigo, da luta do bem contra o mal e de formas repressivas de controle do crime. Nesse sentido, formas menos violentas de atuação das polícias militares seriam uma resultante do processo. Com base nisso, a hipótese a ser testada neste trabalho é se a implantação do policiamento comunitário em São Paulo promoveu redução do uso da força nas ocorrências em que policiais militares sofreram agressões. Com essa perspectiva, pretendese compreender como se deram as ações dos agentes públicos envolvidos em uma situação em que a violência foi a condicionante da interação entre a polícia militar e o cidadão.

A ligação entre policiamento comunitário e uso da força não se constitui uma relação direta nas suas propostas de implantação; todavia, ela traz a ideia de uma mudança cultural e comportamental que promoveria formas menos repressoras e, portanto, menos violentas, nos encontros entre a polícia e a sociedade. Norbert Elias, em $O$ Processo Civilizador (1990), descreve como a interdição social às formas de violência proporcionou as bases para que as pessoas desenvolvessem um comportamento ( habitus) menos violento, o que permitiu a consolidação do monopólio da violência nas mãos de um terceiro, o Estado. Tanto esse movimento psicogenético, de interdição íntima para a prática de atos violentos, como esse processo sociogenético, de concentração do monopólio da violência pelo Estado, proporcionaram as bases para que a violência fosse um recurso cada vem menos acionado na resolução dos conflitos. Essa leitura mais ampla permite pensar se uma disposição no interior das forças policiais no sentido do recurso a formas menos violentas na interação da polícia com a sociedade traria consequências culturais mais amplas sobre como a polícia se coloca frente ao uso da força. Não obstante o fato de os processos de mudança dos valores das instituições serem demorados, as polícias são muito sensíveis às mudanças, apresentando rápidas reorganizações de suas práticas no curto prazo (BUENO, 2014, 2015; OLIVEIRA, 2012), ainda que, em médio e longo prazos, as práticas retomem seus lugares.

Letalidade policial e uso da força nas práticas da polícia militar paulista constituem objeto de preocupação nos dias atuais, em razão das crescentes taxas de mortes decorrentes do trabalho policial observadas nas últimas décadas, com um aumento nos anos de 2017 a 2019. Algumas análises buscam explicar essa recalcitrante permanência. A primeira delas atribui à ligação histórica os aparelhos repressivos que atuaram 
durante o regime militar entre os anos 1964 e 1985. Neste período, as polícias militares passaram a ser responsáveis pelo policiamento ostensivo, absorvendo outras corporações policiais do período, e suas lógicas institucionais se aprofundaram em direção aos modelos militares das Forças Armadas. A presença de grupos de extermínio e o aumento da repressão contra grupos contrários ao regime teriam performado as práticas das polícias militares até os dias atuais (CALDEIRA, 2000; GUERRA, 2016; MANSO, 2012). Assim, as ligações com os modelos essencialmente militares vão além das práticas havidas durante a ditadura civil-militar, mas permanecem enquanto lógica institucional derivadas de um pensamento de enfrentamento ao crime e ao criminoso como se fosse uma guerra (BUENO, 2014), em que os policiais militares tutelam uma concepção de ordem, perpetuada sobre uma concepção de bem contra o mal (BUENO, 2018). Há, no entanto, análises que caminham no sentido de aproximarem suas leituras a problemas que transcendem o período ditatorial brasileiro, para colocarem a polícia em face dos problemas próprios da contemporaneidade (COSTA, 2011; PEREIRA, 2014), situando esse objeto em perspectiva com países que não enfrentaram períodos autoritários, mas cujos órgãos policiais apresentaram semelhanças em relação ao modelo brasileiro. Acredita-se que este trabalho dialoga mais com essa segunda linha de pesquisa.

\section{IMPLANTAÇÃO DO POLICIAMENTO COMUNITÁRIO CONFORME MODELO KOBAN EM SÃO PAULO}

O policiamento comunitário em São Paulo se aprofunda com a adoção do modelo Koban, marcado pela assinatura de um convênio, em 2004, entre a Polícia Militar Estadual (PMESP) e a Agência de Cooperação Internacional Japonesa (Jica). Segundo Souza (2019, p. 42-43), o primeiro Acordo de Cooperação Técnica começou a ser elaborado em 2003 e foi firmado em dezembro de 2004, com vigência de 2005 a 2008, ainda que ambas instituições já viessem operando de modo cooperado desde o ano de 1999, por meio de um compromisso formal de cooperação'.

O modelo de policiamento comunitário trazido do Japão diferenciava-se do vigente na PMESP desde 1997. Ao contrário do modelo trazido dos Estados Unidos, em que problemas ambientais relativos à qualidade de vida em geral do bairro e abordagens a aspectos sociais, como pobreza e desigualdade, são considerados para a formulação das políticas de segurança, o modelo japonês concentra seus esforços em uma prevenção situacional do cometimento dos crimes, seja pelo esforço em conscientização de medidas de autoproteção junto à população, seja pela vigilância nos momentos de eventuais encontros entre vítima e agressor (FERRAGl, 2013). Com esse enfoque, a aposta japonesa investe na capacitação de grupos de policiais estabelecidos em postos policiais, chamados kobans, como referência das medidas de policiamento comunitário. Na PMESP, se, em um primeiro momento, o policiamento comunitário tem a premissa de ser uma filosofia e uma estratégia operacional, passa, a partir do convênio com a Jica, a ser encapsulado nas Bases Comunitárias de Segurança (BCS). A mudança ocorrida a partir do acordo com a Jica marca um novo momento do policiamento comunitário, ao apresentar uma mudança na estratégia de policiamento que, inicialmente, possuía um sentido mais difuso e doutrinário, para uma direção mais localizada, formal e burocrática. Segundo Evanilson Souza, um dos oficiais da PMESP que trabalharam na implantação desse sistema:

As Bases Comunitárias de Segurança [implantadas em 1997], apesar de objetivarem a presença policial militar junto à sociedade, não atenderam todas as expectativas, principalmente pela falta de sistematização do

1 Segundo Silva (2006), já em 1999, a PMESP e a Jica assinam um acordo de cooperação técnica que prevê a instalação de Bases Comunitárias de Segurança (BCS). Todavia, para efeitos deste trabalho, estabelecemos o ano de 2004 em razão do aprofundamento do processo (ALVES, 2013; SOUZA, 2019). 
emprego do efetivo de recursos materiais e, principalmente, de uma forma de atuação, sendo patente que o sucesso ou até mesmo o fracasso das experiências deveu-se, exclusivamente, a fatores personalistas, fato que foi observado pelo Comando e pela própria comunidade. Fizeram-se necessários, então, novos estudos para sua operacionalidade. Diante dessa evolução, em 2004, o acordo de Cooperação Técnica Brasil/Japão, existente desde 1999, foi reiterado para a aplicação entre janeiro de 2005 e janeiro de 2008, período em que o serviço nas Bases Comunitárias de Segurança foi padronizado e sistematizado metodologicamente. (SOUZA, 2019).

Inicialmente, o modelo Koban foi implantado em 8 Bases Comunitárias de Segurança já em funcionamento na cidade de São Paulo, selecionadas dentre as demais por terem se destacado anteriormente "por apresentarem projetos comunitários de relevância e que trouxeram resultados positivos em relação aos índices criminais" (SILVA, 2006, p. 150). Elas se localizavam: na Praça Rotary (bairro Santa Cecília), na Vila das Mercês (bairro Sacomã), na Praça Oscar Silva (bairro Vila Guilherme), na Praça $1^{\circ}$ de Maio (bairro Ermelino Matarazzo), em Britânia (bairro Jaraguá), no Parque do Carmo e no Jardim Ranieri (bairro M’Boi Mirim) e no bairro do Belém. Não significaram novos projetos de construção de edificações em relação ao processo iniciado em 1997, mas uma mudança de sentido, que, a partir de então, passou a adotar o modelo de policiamento japonês Koban. Suas principais inovações foram em treinamento, compra de equipamentos como computador, quadro de atividades e mapa da área com pontos sensíveis, criação e distribuição de formulários-padrão, realização de visitas comunitárias, criação de informativos destinado a orientar a comunidade sobre segurança e a dar visibilidade às ações em andamento pela respectiva BCS, definição de área de atuação, incentivo às reuniões com lideranças, incentivo à criação de projetos comunitários e elaboração de relatórios sobre desordens ambientais, como lixo, má iluminação, buracos na rua e terrenos abandonados (SILVA, 2006, p. 54-55).

Diante da introdução desse modelo de policiamento e em face dos resultados esperados quanto à mudança das práticas da PMESP em sua relação com a sociedade, procurou-se trazer evidências no sentido de avaliar se o policiamento comunitário impactou o uso da força nas ocorrências atendidas pela corporação.

\section{METODOLOGIA}

A PMESP publica, diariamente, em intranet, um resumo de ocorrências do dia anterior. Recebe o nome de Clipping. É disponibilizado em seu formato digital, desde agosto de 2003. Antes disso, sua divulgação era por meio físico (algo como uma apostila ou um caderno distribuído a todas as unidades da corporação). Sua produção ocorre desde, no mínimo, os anos iniciais da década de 1990. É organizado pelo órgão de inteligência da PMESP, que recebe diariamente os relatórios das ocorrências e os compila nessa publicação. Os relatos são agrupados em temas-chave. Traz, via de regra, dados e histórico de ocorrências importantes, dentre as quais apreensões de grande quantidade de objetos provenientes da prática de crimes, manifestações públicas atendidas, mortes ou ferimentos de policiais militares, entre outras. Além dessas, traz as ocorrências que redundaram em mortes ou lesão corporais de civis em decorrência de disparo de arma de fogo efetuado por policiais militares, assim como eventos em que houve disparos de arma de fogo contra policiais militares, ainda que não tenham resultado em morte ou prisões de pessoas. Essas ocorrências são agrupadas, na publicação, e classificadas como "resistência".

"Resistência", para os efeitos de sua classificação no Clipping, é, por sua vez, baseada em uma classificação atrelada às concepções culturais da corporação. Define um determinado evento cujo significado se distancia em parte em relação à definição legal. A "Resistência", no jargão policial, que é incorporada na editoração do Clipping, são as ocorrências em que o policial militar, com uso de arma de fogo, revida a uma 
agressão que se deu com uso de arma de fogo ou arma branca. Sob o aspecto estritamente legal, o crime de "resistência" abrange qualquer oposição legal de ordem de autoridade competente, mediante o uso de violência ou ameaça (BRASIL, 1940), o que amplia as definições de resistência ao trazer não somente os fatos em que há a presença de armas, mas também outras dinâmicas menos violentas. Todavia, no material pesquisado, a presença de disparos de arma de fogo, seja pelo policial militar, seja contra ele, é elemento essencial para que o fato seja considerado uma "resistência". Assim, eventuais prisões pelo crime de resistência, sem o emprego de arma de fogo, não foram reportadas no Clipping por, provavelmente, não serem consideradas ocorrências de gravidade e, por essa razão, não merecerem ser relatadas nesse resumo diário de ocorrências, exceção feita àquelas de maior repercussão, como já relatado acima.

Cabe salientar que as ocorrências que resultam em mortes ou lesões corporais praticadas por policiais no Estado de São Paulo não recebem a classificação de "resistência" desde 2013, quando o termo foi substituído por "morte decorrente de intervenção policial" ou "lesão corporal decorrente de intervenção policial', respectivamente (BUENO, 2014; BUENO; LIMA; TEIXEIRA, 2019). Cabe reafirmar que, neste trabalho, não serão analisadas somente as ocorrências que resultaram mortes ou lesões corporais, mas também aquelas em que pessoas foram presas sem ferimentos, razão pela qual as categorias "mortes e/ ou lesões corporais decorrentes de intervenção policial" não identificam as unidades de análise. Com base nesse suporte, foi possível extrair as dinâmicas das ocorrências classificadas como "resistência" - nos termos acima descritos - pela PMESP, podendo, assim, compreender como se deu o emprego do uso da força nos eventos selecionados. Em razão disso, a partir deste ponto do texto, preferiu-se retirar as aspas quando o termo resistência for escrito, pelo fato de designar, neste trabalho e no universo jurídico, elementos que não se comunicam integralmente com os termos "morte/lesão corporal decorrente de intervenção policial".

A base consultada apresenta uma amostra homogênea dos casos de resistência atendidos pela PMESP em cada ano analisado, pelo fato de que a metodologia institucional foi a mesma nos anos estudados. Assim, possíveis vieses na publicação do Clipping se mantiveram no decorrer dos anos estudados, atribuindo uniformidade longitudinal aos dados analisados. Dessa maneira, ainda que as ocorrências publicadas no periódico possam ter deixado de retratar a totalidade dos eventos no período, a quantidade de registros analisados (1126) permite análises internas quanto ao fenômeno analisado.

A versão digital do Clipping foi disponibilizada a partir de $1^{\circ}$ de agosto de 2003, o que exigiu a elaboração de um pedido junto ao Centro de Inteligência para os registros anteriores. A resposta trouxe as resistências havidas entre janeiro e julho de 2003. De posse desse material, foi feita a leitura de todas as edições do Clipping, extraindo as ocorrências classificadas como resistência, ocorridas na cidade de São Paulo, entre $1^{\circ}$ de janeiro de 2003 e 31 de dezembro de 2005. Foram, a partir de então, extraídas informações como data, endereço (consequentemente se o evento se deu em área abrangida no projeto de Policiamento Comunitário), quantidade de pessoas mortas, quantidade de pessoas feridas, quantidade de pessoas presas ilesas e se houve fuga. Essas variáveis permitiram analisar as dinâmicas quanto ao resultado de "pessoas mortas", "pessoas lesionadas" e "pessoas presas ilesas", dentre as ocorrências de resistência atendidas nos anos de 2003 e 2005 na cidade de São Paulo, de forma a permitir inferências quanto ao emprego do uso da força pela PMESP. Essa metodologia permitiu estabelecer comparações entre os eventos havidos na cidade de São Paulo, desagregando-os entre as áreas das Companhias de Policiamento em que o policiamento comunitário Koban foi implantado e aquelas não abrangidas pelo projeto.

O período analisado, 2003 a 2005, tem o propósito de buscar mensurar tais hipóteses a partir do curto prazo da implantação da política, uma vez que se acredita que seus efeitos são mais efetivos quanto mais recente 
for sua implementação, cujo vigor institucional, contrariamente, diminuiria no transcorrer do tempo. Dessa forma, buscou-se analisar se a implantação do policiamento comunitário nesses territórios impactou o uso da força nos atendimentos das ocorrências de resistência, por meio dos resultados finais das ocorrências, quais sejam mortes, lesões corporais ou presos ilesos. A hipótese que subjaz a essa questão se alicerça na suposição de que orientações mais comunitárias da oferta de serviços policiais sejam indutoras de uma mudança cultural no interior das corporações policiais que privilegiassem formas menos repressivas para a solução das questões de segurança pública e, portanto, menos recorrentes ao uso da força.

\section{RESULTADOS ALCANÇADOS}

A pesquisa junto ao Clipping da PMESP trouxe o total de 1126 ocorrências de resistências entre 2003 e 2005, na cidade de São Paulo, que redundaram em morte, lesão corporal, prisão (sem ferimentos) ou fuga dos envolvidos. Esses resultados não são excludentes entre si em relação ao desfecho da ocorrência, haja vista que, pela eventual presença de mais uma pessoa, podem ser encontrados resultados diversos ("morte + lesão corporal + presos ilesos", "morte + presos ilesos - lesão corporal" etc.) e simultâneos em uma mesma ocorrência. Do universo de 1126 ocorrências, em 57 delas, ou 5,06\%, todas as pessoas envolvidas fugiram. Por essa razão, esse conjunto foi desconsiderado das análises, pois pouco contribuem para investigação dos resultados dos eventos, haja vista não permitirem afirmar se as pessoas foram feridas.

\section{TABELA 1}

Ocorrências de resistência atendidas pela Polícia Militar/SP na cidade de São Paulo (2003-2005)

\begin{tabular}{|c|c|c|c|c|c|c|c|c|}
\hline & \multicolumn{2}{|c|}{2003} & \multicolumn{2}{|c|}{2004} & \multicolumn{2}{|c|}{2005} & \multicolumn{2}{|c|}{ Total } \\
\hline & $\mathrm{N}$ & $\%$ & $N$ & $\%$ & $\mathrm{~N}$ & $\%$ & $\mathrm{~N}$ & $\%$ \\
\hline Ocorrências sem prisão de pessoas & 12 & 2,60 & 25 & 6,60 & 20 & 7,02 & 57 & 5,06 \\
\hline $\begin{array}{l}\text { Ocorrências com prisão (lesão } \\
\text { corporal e ilesas) de pessoas ou morte } \\
\text { de pessoas }\end{array}$ & 450 & 97,40 & 354 & 93,40 & 265 & 92,98 & 1069 & 94,94 \\
\hline Total & 462 & 100,00 & 379 & 100,00 & 285 & 100,00 & 1126 & 100,00 \\
\hline Todas as pessoas foram mortas & 213 & 47,33 & 143 & 40,40 & 71 & 26,79 & 427 & 39,94 \\
\hline Todas as pessoas foram lesionadas & 65 & 14,44 & 64 & 18,08 & 62 & 23,40 & 191 & 17,87 \\
\hline $\begin{array}{l}\text { Todas as pessoas foram presas (sem } \\
\text { lesões) }\end{array}$ & 21 & 4,67 & 49 & 13,84 & 53 & 20,00 & 123 & 11,51 \\
\hline $\begin{array}{l}\text { Todas as pessoas foram mortas ou } \\
\text { lesionadas, sem prisão de pessoas em } \\
\text { outras condições (ilesas) }\end{array}$ & 29 & 6,44 & 12 & 3,39 & 8 & 3,02 & 49 & 4,58 \\
\hline $\begin{array}{l}\text { Todas as pessoas mortas ou presas } \\
\text { ilesas }\end{array}$ & 55 & 12,22 & 40 & 11,30 & 21 & 7,92 & 116 & 10,85 \\
\hline $\begin{array}{l}\text { Todas as pessoas foram lesionadas ou } \\
\text { presas ilesas }\end{array}$ & 56 & 12,44 & 41 & 11,58 & 47 & 17,74 & 144 & 13,47 \\
\hline $\begin{array}{l}\text { Todos foram mortos, lesionados ou } \\
\text { presos ilesos }\end{array}$ & 11 & 2,44 & 5 & 1,41 & 3 & 1,13 & 19 & 1,78 \\
\hline $\begin{array}{l}\text { Total de ocorrências com prisão } \\
\text { (lesão corporal e ilesas) de pessoas } \\
\text { ou morte de pessoas }\end{array}$ & 450 & 100,00 & 354 & 100,00 & 265 & 100,00 & 1069 & 100,00 \\
\hline
\end{tabular}


Das 1069, ou 94,94\%, ocorrências que resultaram em alguma forma de custódia, seja morte, lesão corporal ou prisão sem lesões, em 427, ou 39,94\%, não houve sobreviventes; em 191, ou 17,87\%, todas as pessoas sofreram lesões corporais, e em 123, ou 11,51\%, todas as pessoas foram presas sem lesões. O conjunto mostra uma predominância de ocorrências em que todos morrem, seguido por ocorrências em que todos ficam feridos e, por último, por ocorrências em que todos são presos sem danos.

Essas categorias foram analisadas em concomitância. Todas as pessoas foram lesionadas ou presas ilesas em 144 ocorrências, ou 13,47\%; todas foram mortas ou presas ilesas em 116 ocorrências, ou 10,85\%; todas foram mortas ou lesionadas em 49 ocorrências, ou 4,58\%. A presença de mortos, pessoas presas lesionadas e ilesas se deu em 19 ocorrências, ou 1,78\%, dos fatos analisados.

Em uma análise longitudinal (2003-2005), verifica-se que dentre os eventos analisados, o resultado das ocorrências variou significativamente. Para a variável "mortos", isolada ou cumulativamente, ocorreu uma variação negativa, com uma queda de 20,54\% para "todos mortos", 3,43\% para "todos mortos ou lesionados" e 4,30\% para "todos mortos ou presos ilesos". As resistências com a ocorrência de pessoas feridas, isolada ou cumulativamente, apresentaram variação positiva de 8,95\% para "todos ficam lesionados" e de 5,29\% para "todos ficam lesionados ou são presos sem lesões"; a presença de pessoas lesionadas teve variação negativa apenas quando combinadas com mortes, com queda relativa de 4,30\%, como já trazido acima. Já "pessoas presas sem apresentarem lesões corporais" apresentaram uma variação positiva, de 15,33\% para "todos presos sem lesões" e 5,29\% para "todos presos ilesos ou com lesões". Tal qual o observado quanto às lesões corporais, a variável "preso ileso" apresentou variação negativa, 4,30\% apenas quando foi associada a mortes.

\section{GRÁFICO 1}

Resultados das ocorrências de resistência atendidas pela Polícia Militar/SP na cidade de São Paulo (2003-2005)

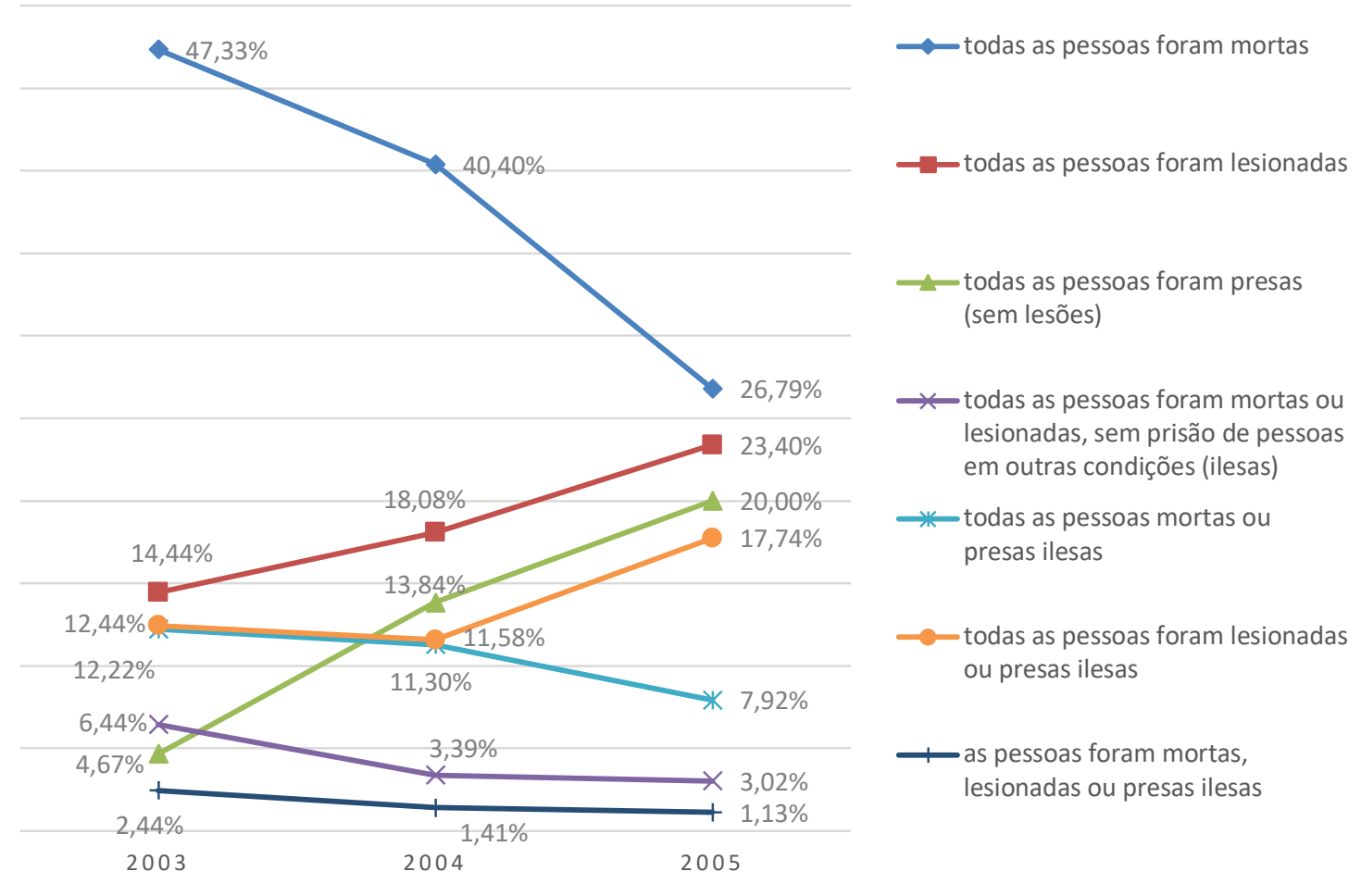

Fonte: Centro de Inteligência da Polícia Militar/SP. Elaboração própria. 
Com o intuito de avaliar o impacto da implantação do policiamento comunitário, as ocorrências foram categorizadas em dois diferentes grupos, conforme o local onde as pessoas foram mortas ou presas (com ou sem lesões): Companhias de Policiamento com e sem a implantação de policiamento comunitário. Feito isso, foram analisadas as variáveis já trazidas acima. Elas resultaram em 84 ocorrências, ou 7,86\%, em territórios de implantação de policiamento comunitário e 984, ou 92,14\%, em outros territórios da cidade de São Paulo. Os percentuais são em função do total de ocorrências atendidas, naquele ano, por território analisado, o que permitiu analisar as variações dentro de um mesmo conjunto. Em outras palavras, os percentuais não são em função do total de "resistências" na cidade de São Paulo, mas representam a participação dentre as ocorrências havidas nos territórios "com" ou "sem" a implantação de policiamento comunitário. Não obstante a simultaneidade das três diferentes categorias em uma mesma ocorrência, serão trazidos os resultados nos quais os desfechos não têm variação, ou seja, ou "todos morrem" ou "todos são lesionados" ou "todos são presos ilesos".

O percentual de resistências em que todas as pessoas morreram apresentou variação negativa para ambos os grupos, tendo sido maior a queda dentre o grupo de companhias sem projeto de policiamento comunitário (-21,11\%) que naquelas abrangidas pelo projeto (-13,57\%) (Gráfico 2).

\section{GRÁFICO 2}

\section{Resultado das ocorrências de resistência atendidas pela Polícia Militar/SP na cidade de São Paulo em que todas as pessoas foram mortas (2003-2005)}

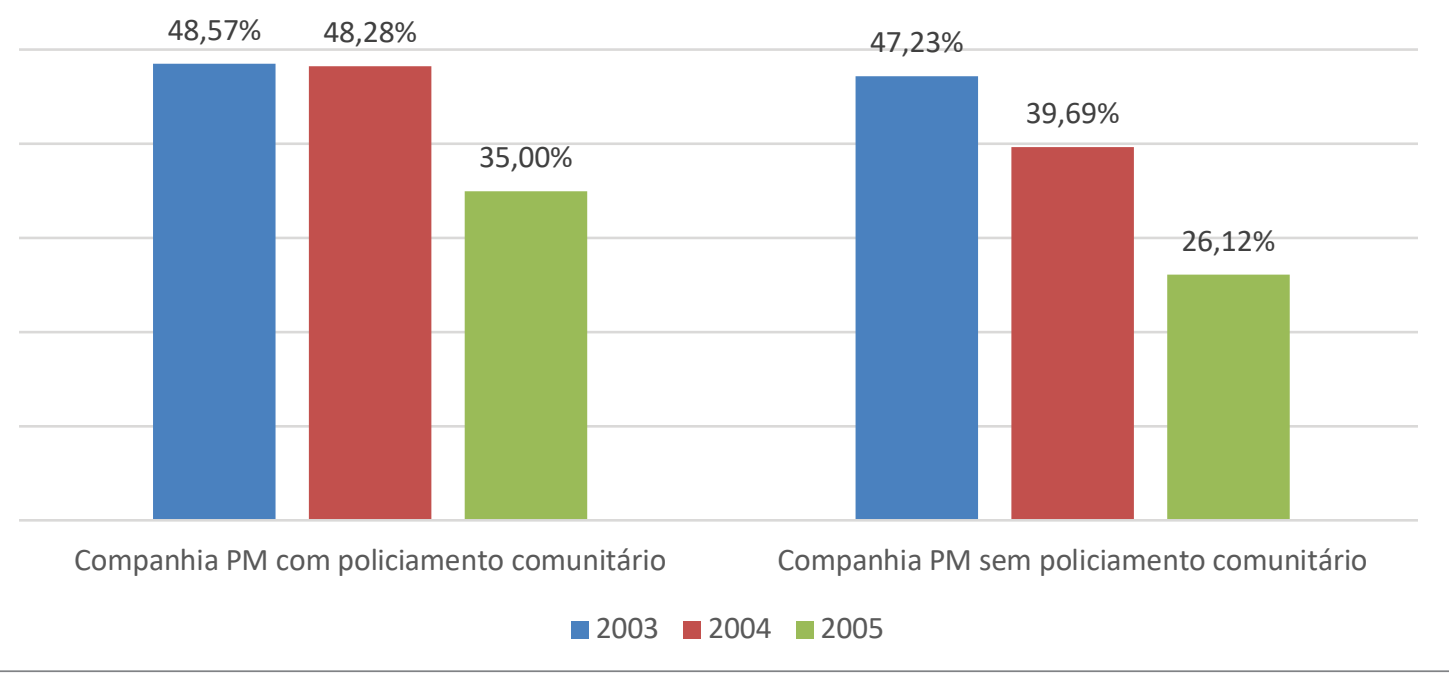

Fonte: Centro de Inteligência da Polícia Militar/SP. Elaboração própria.

O percentual de ocorrências em que todas as pessoas foram lesionadas apresentou variação positiva para ambos os grupos, havendo uma aceleração a partir do ano de 2004 para o grupo de companhias com a implantação do projeto de policiamento comunitário. Enquanto esse grupo apresentou uma variação de 13,57\%, o outro grupo, daquelas companhias não abrangidas pelo projeto de policiamento comunitário, exibiu uma variação de 8,57\% (Gráfico 3). 


\section{GRÁFICO 3}

Resultado das ocorrências de resistência atendidas pela Polícia Militar/SP na cidade de São Paulo em que todas as pessoas foram feridas (2003-2005)

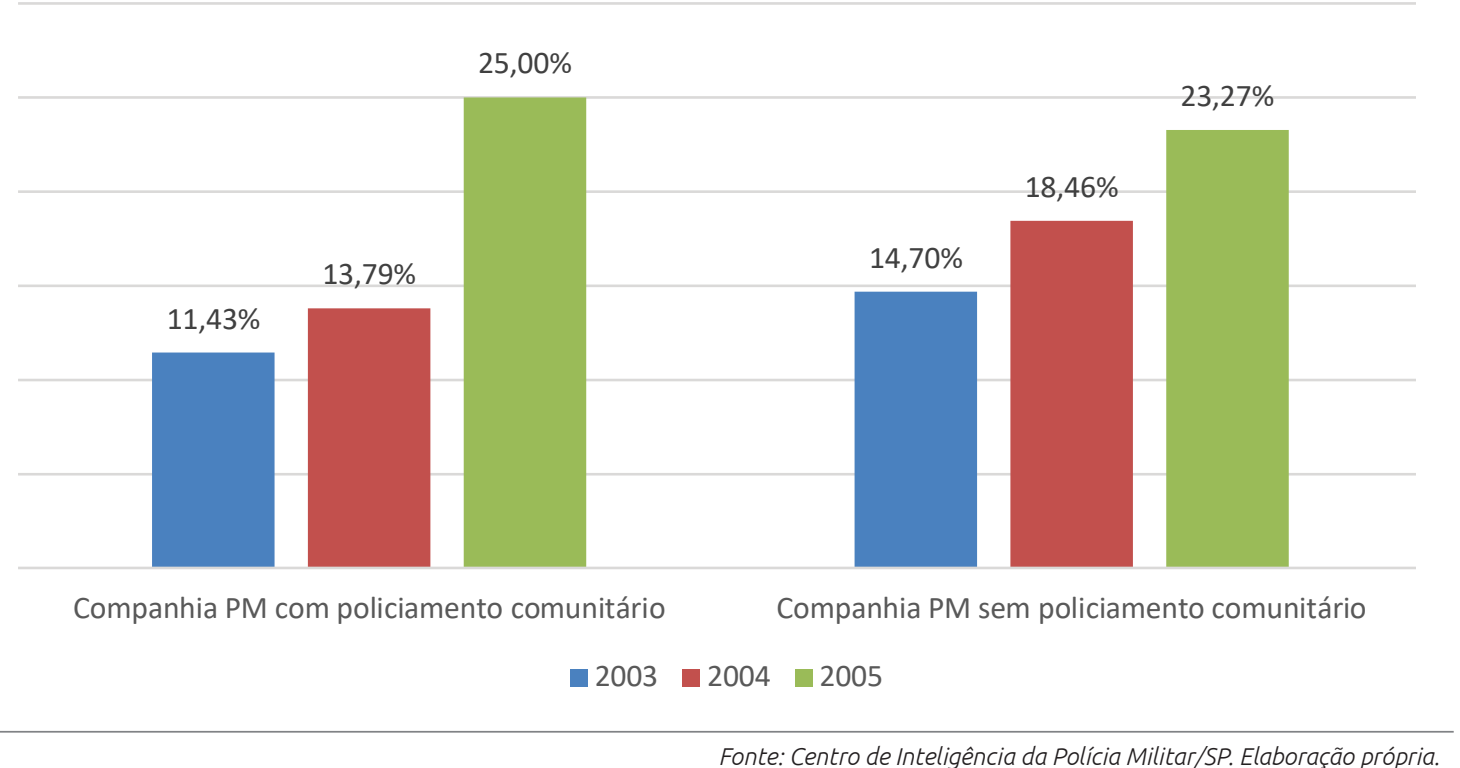

No que se refere ao conjunto das ocorrências em que todas as pessoas foram presas sem que fossem feridas, ambos os grupos apresentaram uma variação positiva: 14,29\% para o grupo de companhias com a implantação do projeto de policiamento comunitário e 15,42\% para o grupo sem a implantação do projeto (Gráfico 4).

\section{GRÁFICO 4}

Resultado das ocorrências de resistência atendidas pela Polícia Militar/SP na cidade de São Paulo em que todas as pessoas foram presas ilesas (2003-2005)

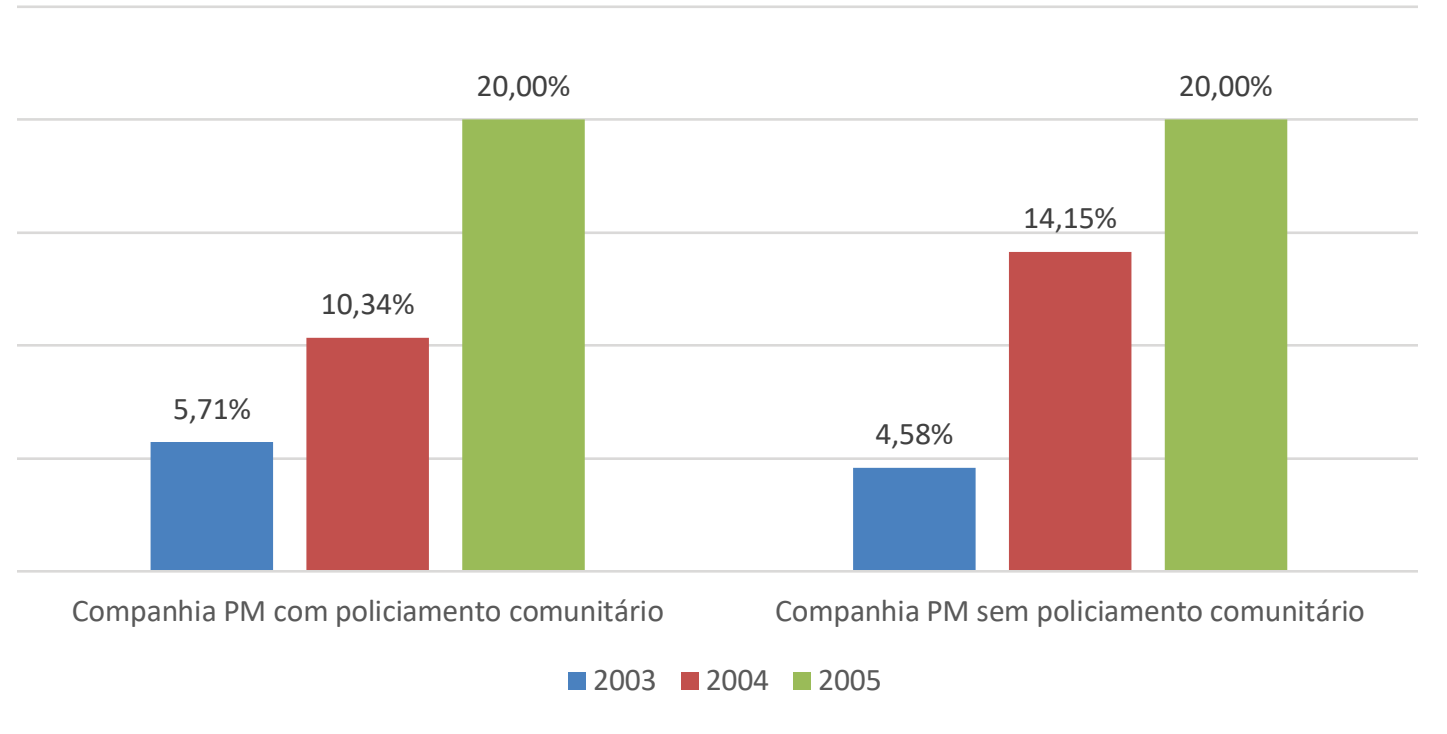




\section{DISCUSSÃO}

Os resultados mostram que houve uma variação negativa para ambos os grupos quanto ao resultado morte nas resistências atendidas pela PMESP no período; todavia, esse resultado se fez mais presente nas companhias sem a implantação do projeto de polícia comunitária que naquelas com a implantação do projeto, (com exceção às ocorrências em que todos foram lesionados, o que indica menores níveis de uso da força em companhias com policiamento comunitário). De toda sorte, em face das premissas da política, acreditava-se que os resultados indicassem uma prevalência ainda maior de redução do uso da força em relação àquelas unidades envolvidas no projeto. Não foi o que se verificou. Assim, algumas hipóteses explicativas podem ser levantadas.

A primeira delas diz respeito às limitações estatísticas da amostra, pois a distância quantitativa (958 casos versus 84 casos) entre os grupos não permitiria que fosse realizada uma comparação substantiva entre eles, o que indicaria que os instrumentos utilizados não seriam capazes de testar as hipóteses iniciais. Todavia, essa limitação não poderia ser contornada pelo prolongamento da escala temporal, pois, além de ter a propensão de manter as diferenças numéricas, alcançaria períodos de menores impactos da política pública, interferindo na correlação. De toda forma, pelo fato de as análises tratarem de movimentos endógenos a ambos os grupos, acredita-se que sejam eficazes para analisar o problema colocado.

As demais explicações referem-se à questão da correlação entre policiamento comunitário e uso da força pelas polícias. Cabe dizer que não foram encontradas análises nesse sentido, não obstante a implantação dessa política pública ter sido objetivo de reiteradas avaliações, tais como em Kahn (2003), Universidade Federal de Minas Gerais (2009), Oliveira (2012), Tavares dos Santos et al. (2013), Ribeiro, Oliveira e Diniz (2016), Riccio et al. (2017). Tem-se, de forma geral e imanente, que o policiamento comunitário teria a capacidade de promover formas menos violentas de intervenção pelas polícias.

Dito isso, a segunda hipótese é a de que o policiamento comunitário não tem o efeito de produzir menores níveis de uso da força. Análises nacionais e internacionais apontam que uma das consequências da implantação do policiamento comunitário é que, ao mesmo tempo em que estabelece melhores laços entre a polícia e as comunidades a que se destinam, acentua, de maneira contrafactual, antigas práticas contra populações que não faziam parte daquele específico segmento social, configurando um recorte social denominado "anticomunidade" (Roussel, 2013), formado em função de recortes de raça, condição econômica e status social. No caso brasileiro, a existência de um amplo espectro acionado pelos operadores e gestores de segurança pública dá margem para estratégias que vão desde projetos sociais, ocupação de territórios e prisão de criminosos (REIS, 2005; RIBEIRO, 2014; RIBEIRO; OLIVEIRA; DINIZ, 2016), reconfigurando o sentido pretendido com a política pública e cooptando o projeto para legitimar velhas práticas. Assim, o policiamento comunitário, contrariamente às suas pretensões iniciais, constituise em novas formas de vigilância contra os grupos já historicamente objetos das intervenções policiais (LOCHE, 2012). Nesse diapasão, a implantação do policiamento comunitário pela PMESP teria aprofundado formas violentas de intervenção, o que, apesar de não poder ser constatado para o período analisado, pode dar sustentação explicativa quanto às altas taxas de letalidade policial observada em períodos além do estudado no presente trabalho (BUENO, 2018; BUENO; LIMA; TEIXEIRA, 2019). Nesse mesmo sentido, algumas análises apontam que as permanências das velhas práticas policiais, agora adornadas com nova roupagem, foram encontradas também no policiamento comunitário em Belo Horizonte (RIBEIRO; OLIVEIRA; DINIZ, 2016), Rio de Janeiro (MONTEIRO, 2005; RIBEIRO; MONTANDON, 2015), Salvador (REIS, 
2005) e São Paulo (FERRAGI, 2013), cujos programas não foram capazes de reformar as polícias militares ou ao menos propor tais mudanças de maneira vigorosa. Dessa forma, a redução das mortes observadas em 2005 (BUENO, 2014) ou do uso da força no atendimento das ocorrências seriam decorrentes de outras causas que não ligadas à implantação do policiamento comunitário, tal qual aponta Samira Bueno:

Entre 2002 e 2004 houve tendência ascendente dos índices de letalidade policial, período em que o coronel Alberto Silveira Rodrigues esteve no comando da PMESP. Substituído pelo coronel Elizeu Eclair Teixeira Borges, a polícia militar registrou letalidade policial decrescente abrupta em 2005. Em análise dos membros da comissão sobre o período, duas conclusões principais são acionadas: 1) a mudança no comando da PM teve impacto direto na redução desse índice, já que o coronel Eclair faz parte de uma "[...] linha mais moderada no que diz respeito à violência policial"; 2) o episódio da morte do dentista negro Flávio Sant’Anna, conforme já citado, assassinado por policiais militares por engano, causou grande repercussão na mídia e provocou uma série de reuniões e orientações internas na PM, bem como "[...]o sentimento de que o incidente passou dos limites" (ambas as citações constam de documento interno da Comissão de Letalidade). (BUENO, 2014, p. 116).

A terceira explicação para a redução do uso da força no período segue no sentido de que o policiamento comunitário tem o efeito de produzir menores níveis de uso da força, haja vista que a redução do uso da força coincide com a implantação do policiamento comunitário em São Paulo. Nessa hipótese, pode-se defender que enquanto para os territórios em que foi implantada, o policiamento comunitário significou medidas pontuais de gestão das Bases Comunitárias de Segurança já instaladas, como já tratado anteriormente, para o restante da corporação, mais distantes do pragmatismo da implantação, ressoa com uma disposição mais geral de aproximação comunitária, o que indicaria uma disposição mais profunda por parte do governo e da alta direção da Polícia Militar em refutar o uso da força. Para tanto, com o intuito de aprofundar essa discussão, foram analisadas as dinâmicas da Companhia em que foi instalada a Base Comunitária de Segurança do Jardim Ranieri, na qual o projeto de policiamento comunitário atingiu os maiores níveis de reconhecimento, sendo premiado em duas edições do Prêmio Polícia Cidadã (2005 e 2006), promovido pelo Instituto Sou da Paz, e com o Concurso Nacional de Polícia Comunitária Senasp/Motorola (2005) (SILVA, 2006). Alia-se a isso o fato de seu comandante de Companhia à época, capitão Gilberto Tardochi da Silva, ter se destacado por suas iniciativas em prol do projeto, alcançando, dali a alguns anos, a função de chefe da diretoria de Policiamento Comunitário e Direitos Humanos da PMESP. Acredita-se que, com essa análise, seja possível aproximar-se de compreender se o policiamento comunitário nos moldes implantados teve a capacidade de atingir alguma mudança comportamental para além dos policiais militares envolvidos com o projeto. Diferentemente dos outros gráficos, que apresentaram o resultado percentual dos resultados das dinâmicas das ocorrências, o Gráfico 5 exibe a diferença entre os resultados das ocorrências de 2005 e 2003. 
Variação dos resultados das ocorrências de resistência atendidas pela Polícia Militar/SP na cidade de São Paulo (2003-2005)

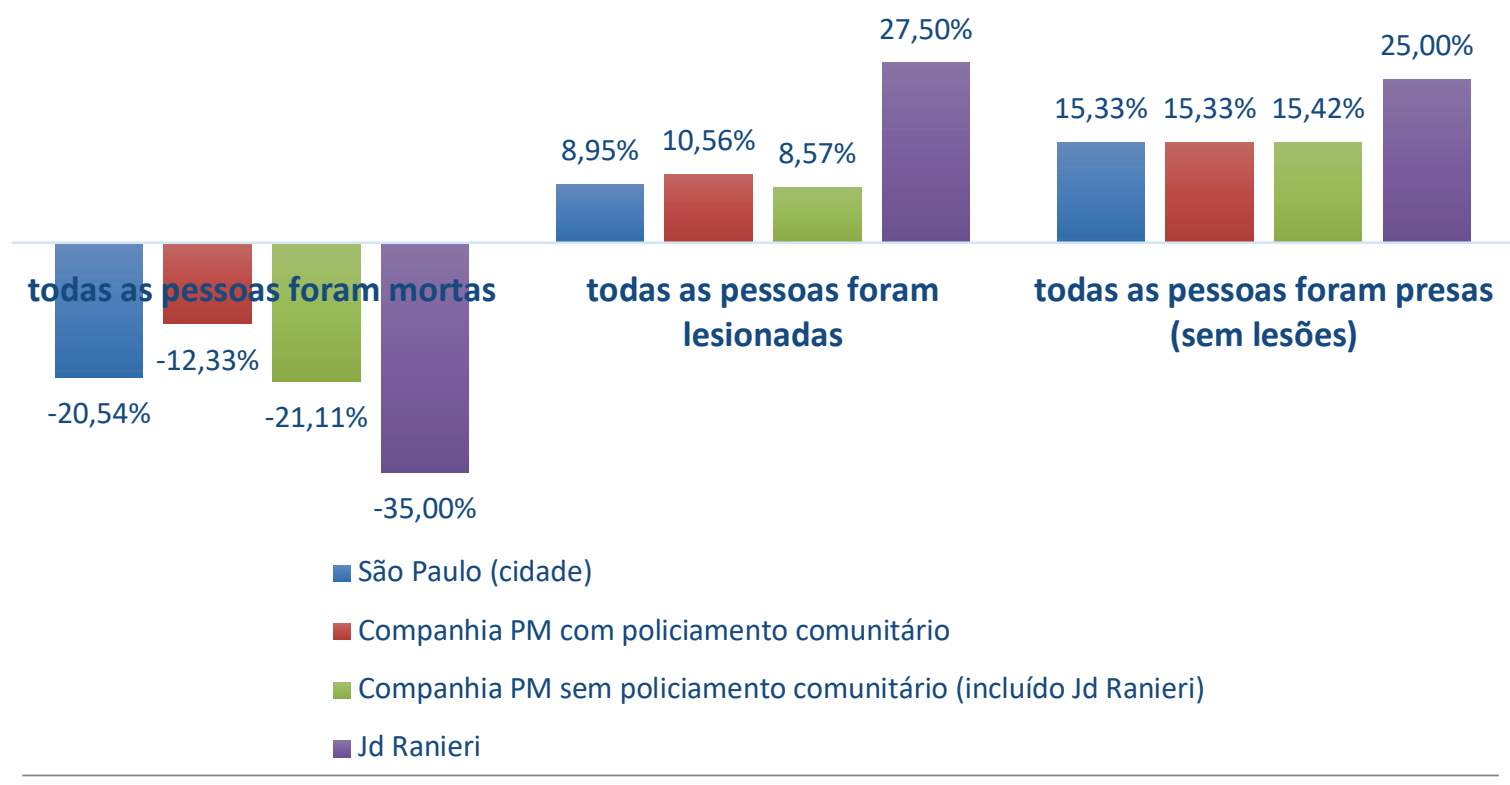

Fonte: Centro de Inteligência da Polícia Militar/SP. Elaboração própria.

Houve 26 ocorrências de resistência na Companhia em que a Base Comunitária de Segurança do Jardim Ranieri se localizava, o que equivale a $2,43 \%$ do total estudado. Verifica-se que a variação do resultado morte nos eventos apresentou uma diminuição se comparada com o restante da cidade de São Paulo ou com as demais Companhias inseridas no projeto de implantação, ao mesmo tempo em que, também comparativamente aos demais grupos, houve maior percentual de pessoas presas feridas e presas ilesas, indicando que, em uma gradação do uso da força, as ações praticadas pelos policiais militares foram menos violentas.

Atribuímos os menores níveis de uso da força no Jardim Ranieri à profundidade que o policiamento comunitário atingiu naquele território em relação às demais Companhias do projeto. Como pontos a serem brevemente elencados, têm-se maior envolvimento da liderança policial e dos policiais militares operadores da BCS Ranieri.

Para o microcosmo da BCS, portanto, o "mundo de fora" também inclui o mundo burocrático (médios e altos oficiais). Eles impõem politicas incongruentes, surgidas de caminhos administrativos e acadêmicos que são distantes das realidades das ruas. Em parte, isso explica porque sargentos se sentem insatisfeitos e desmotivados quando seus comandantes de companhia não se importam ou não apoiam os esforços relacionados às BCS no modelo koban. A BCS Ranieri (bastante influenciada pelo koban), pelo contrário, representa um caso onde tais contradições diminuíram pela intensa informação entre os diferentes níveis hierárquicos. (FERRAGI, 2013, p. 61, grifo nosso, tradução livre).

Alia-se a isso o fato que a implantação e a consolidação do policiamento comunitário no Jardim Ranieri envolveram um conjunto plural de atores locais, tanto estatais, como o Ministério Público (SILVA, 2006), como não-estatais, como, por exemplo, o Fórum em Defesa da Vida Contra a Violência, constituído em 
1996 pela Região Pastoral do M’Boi Mirim, pelo Centro de Direitos Humanos e Educação Popular do Campo Limpo e pela Central de Movimentos Populares do Campo Limpo (SILVA, 2006, p. 76). Esse arranjo político-social, aliado ao envolvimento das lideranças policiais, pode ter tido a capacidade de promover mudanças na cultura policial, seja pela mudança na percepção por parte dos policiais quanto ao ambiente em que trabalham, seja por uma maior vigilância sob suas práticas.

\section{CONCLUSÃO}

As políticas públicas requerem avaliações periódicas de suas ações com a finalidade de aferir seus impactos e, assim, reorientar os rumos adotados. A segurança pública, cujo campo reúne uma série de iniciativas de gestores políticos e policiais, carece de trabalhos que consubstanciem um determinado corpo de práticas que orientem as decisões sobre como auferir ganhos em relação à segurança das pessoas concomitantemente ao respeito aos direitos civis e ao Estado de Direito. Nessa lacuna, a sociedade brasileira fica refém da má gestão do Estado pelo fato de que, mesmo com o empenho de considerável parcela de recursos públicos, se vê vítima ora da criminalidade ora da violência estatal.

Uma das mais eloquentes apostas para novos patamares em segurança pública permanece sendo o policiamento comunitário, que promete a entrega de menores níveis de crime e de ganhos de confiança em relação às polícias. Uma parcela dos trabalhos que se dedicaram a avaliar seus resultados traz os impactos positivos da implantação, como o aumento da sensação de segurança ainda mais significativamente quanto maior for a proximidade com a polícia (CARDIA et al., 2003; KAHN, 2003; RICCIO et al., 2017). Por outro lado, legitimação de velhas práticas sob nova roupagem, permanência da centralização da burocracia policial e aprofundamento das clivagens econômicas, sociais e étnicas se colocam como pontos negativos ao policiamento comunitário.

Neste artigo, procurou-se, em específico, analisar a correlação entre essa política e o uso da força pelas polícias militares. Dialoga com a pesquisa publicada por Emanuel Nunes de Oliveira (2012) que, recorrendo a modelos quantitativos, buscou avaliar se as mortes produzidas por policiais militares de São Paulo atendiam a critérios ligados ao território em que eles trabalhavam ou se tinham correlação com as mudanças em relação às políticas de segurança pública adotadas pelos governos estaduais. Para o autor, há uma "clara relação entre a plataforma política do Executivo e o tipo de padrão da polícia" (op. cit., p. 42). Assim, se há essa correlação, as configurações introduzidas pelo policiamento comunitário, ao se constituir um discurso governamental, também traria redução da letalidade policial?

Os resultados apontam que o modelo Koban implementado na PMESP a partir de 2004 pode ter tido a capacidade de ter impactado a corporação como um todo, mas seus efeitos foram menos eficazes nas Companhias de Policiamento inseridas no projeto. Acreditamos que isso se deva ao fato de que para a PMESP, como um todo, a notícia da implantação do policiamento comunitário tenha ressoado como uma nova diretiva política, enquanto que para aqueles diretamente envolvidos tenha representado um realinhamento mais burocrático que filosófico. No entanto, na Companhia de Policiamento do Jardim Ranieri, onde o projeto foi além dessa mobilização essencialmente técnica e promoveu mudanças tanto mais profundas no ambiente policial, como mobilizou uma rede mais ampla e plural de participantes, os resultados foram os mais expressivos. Com isso, pretendemos afirmar que o policiamento comunitário dispõe de ferramentas para promover menores níveis de emprego da força letal pelas polícias. Porém, 
assim como as demais ações do Estado, a participação social e, sobretudo, a constante busca pela construção da democracia são condições indispensáveis, tanto na promoção de ações mais eficientes, quanto, e principalmente, na consolidação de uma sociedade mais inclusiva.

\section{REFERÊNCIAS BIBLIOGRÁFICAS}

ALVES, B. B. M. P. Avaliação comparativa da cooperação internacional descentralizada e centralizada: 0 Projeto de Polícia Comunitária -Sistema KOBAN no município de São Paulo. Trabalho de Conclusão de Curso (Pós-Graduação em Relações Internacionais) - Instituto de Relações Internacionais, Universidade de São Paulo (IRI/USP), São Paulo, 2013. Disponível em: http://143.107.26.205/documentos/defesa_13-09-12_ Barbara_Beatriz_Maia_Pinto_Alves.pdf. Acesso em: 15 fev. 2020.

BOWLING, B.; PARMAR, A.; PHILLIPS, C. Policing minority ethnic communities. In: NEWBURN, T. (Ed.). Handbook of Policing. 2. ed. Cullompton: Willan Pub., 2008, p. 611-641.

BRASIL (EXECUTIVO). Portaria n 43, de 18 de abril de 2019. Institui a Diretriz Nacional de Polícia Comunitária e cria o Sistema Nacional de Polícia Comunitária. Brasília: Diário Oficial da União/Ministério da Justiça e Segurança Pública, 2019.

BRASIL (LEGISLATIVO). Decreto-Lei n².848, de 7 de dezembro de 1940. Código Penal. Disponível em: http://www.planalto.gov.br/ccivil_03/decreto-lei/del2848compilado.htm. Acesso em: 27 fev. 2020.

BUENO, S. Bandido bom é bandido morto: a opção ideológico-institucional da política de segurança pública na manutenção de padrões de atuação violentos da polícia militar paulilsta. Dissertação (Mestrado em Administração Pública e Governo) - Escola de Administração de Empresas de São Paulo, Fundação Getúlio Vargas, São Paulo, 2014.

BUENO, S. Letalidade na Ação Policial: os Desafios para a Consolidação de uma Agenda de Políticas Públicas no Estado de São Paulo. Administração Pública e Gestão Social, v. 7, n. 1, p. 9-15, 2015.

BUENO, S. Trabalho sujo ou missão de vida? Persistência, reprodução e legitimidade da letalidade na ação da PMESP. Tese (Doutorado em Administração Pública e Governo) - Escola de Administração de Empresas de São Paulo, Fundação Getúlio Vargas, São Paulo, 2018.

BUENO, S.; LIMA, R. S. de; TEIXEIRA, M. A. C. Limites do uso da força policial no Estado de São Paulo. Cadernos EBAPE.BR, v. 17, edição especial, p. 783-799, 2019.

CALDEIRA, T. P. do R. Cidade de Muros: Crime, Segregação e Cidadania em São Paulo. São Paulo: Editora 34/Edusp, 2000.

CARDIA, N.; NETO, P. M.; LOCHE, A.; RUOTTI, C.; NEME, C.; BRITO, E.; FERREIRA, H.; SOUZA, J. L. de; ALVES, R.; CUBAS, V. O policiamento que a sociedade deseja. Relatório. São Paulo: Instituto São Paulo contra a Violência/NEVUSP, 2003.

COSTA, A. T. M. Entre a lei e a ordem: violência entre as reformas nas polícias do Rio de Janeiro e Nova York. São Paulo: Editora FGV, 2004.

COSTA, A. T. M. Police brutality in Brazil: Authoritarian legacy or institutional weakness?. Latin American Perspectives, v. 38, n. 5, p. 19-32, 2011.

ELIAS, N. O Processo Civilizador. Rio de Janeiro: Jorge Zahar, 1990. 
FERRAGI, C. A. Disorganizing and Reorganizing the front lines of community policing: institutional aspects of the Japanese Koban System in São Paulo. Revista Brasileira de Segurança Pública, v. 7, n. 2, p. 50-66, 2013. FRANÇA, F. G. As ilusões do policiamento comunitário: o caso da Paraíba. Revista de Políticas Públicas, v. 23, n. 1, p. 62-80, 2019.

FRÜHLING, H. The Impact of International Models of Policing in Latin America: The Case of Community Policing. Police Practice and Research, v. 8, n. 2, p. 125-144, 2007.

GUERRA, M. P. Polícia e ditadura: a arquitetura institucional da segurança pública de 1946 a 1988. Brasília: Ministério da Justiça e Cidadania, 2016. [Coleção LAB-MDH laboratório de tecnologia para pesquisa em memória e direitos humanos, v. 1].

HEYER, G. D. Ghosts of Policing Strategies Past: Is the New Zealand Police 'Prevention First' Strategy Historic, Contemporary or the Future?. Public Organization Review, v. 16, n. 4, p. 529-548, 2016.

KAHN, T. Segurança pública e trabalho policial no Brasil. Working Paper 51. Universidade de Oxford: Centre for Brazilian Studies, 2003. Disponível em: https://www.lac.ox.ac.uk/sites/default/files/lac/ documents/media/tulio20khan2051.pdf. Acesso em: 20 dez. 2019.

LOCHE, A. A. Segurança e Controle Social: uma análise do Policiamento Comunitário. Tese (Doutorado em Sociologia) - Faculdade de Filosofia, Letras e Ciências Humanas, Universidade de São Paulo (FFLCH/ USP), São Paulo, 2012.

MANSO, B. P. Crescimento e queda dos homicídios em SP entre 1960 e 2010: uma análise dos mecanismos da escolha homicida e das carreiras no crime. Tese (Doutorado em Ciências Políticas) - Faculdade de Filosofia, Letras e Ciências Humanas, Universidade de São Paulo (FFLCH/USP), São Paulo, 2012.

MONTEIRO, M. F. O Policiamento Comunitário como alternativa à democratização da polícia. Dissertação (Mestrado em Direito) - Universidade Cândido Mendes, Rio de Janeiro, 2005.

MUNIZ, J.; CARUSO, H.; FREITAS, F. Os estudos policiais nas ciências sociais: um balanço sobre a produção brasileira a partir dos anos 2000. Revista Brasileira de Informação Bibliográfica em Ciências Sociais, v. 84, p. 148-187, 2018.

MUNIZ, J. "Ser policial é, sobretudo, uma razão de ser": cultura e cotidiano da Polícia Militar do Estado do Rio de Janeiro. Tese (Doutorado em Ciência Política) - Instituto Universitário de Pesquisas do Rio de Janeiro, Rio de Janeiro, 1999.

MUNIZ, J.; PAES-MACHADO, E. Polícia para quem precisa de polícia: contribuições aos estudos sobre policiamento. Caderno CRH, v. 23, n. 60, p. 437-447, dez. 2010.

OLIVEIRA, E. N. Políticas públicas e estratégias de controle da ação letal das instituições policiais no Estado de São Paulo. Revista Brasileira de Segurança Pública, v. 6, n. 1, p. 28-47, 2012.

PEREIRA, A. W. Politics versus Policy: Is Police Politicization a Threat to Democracy in Brazil?. Teoria e Pesquisa, v. 23, n. 1, p. 6-28, 2014.

REIS, V. Atucaiados pelo Estado: as políticas de segurança pública implementadas nos bairros populares de Salvador e suas representações, 1991-2000. Dissertação (Mestrado em Ciências Sociais) - Universidade Federal da Bahia, Salvador, 2005. Disponível em: http://repositorio.ufba.br/ri/handle/ri/13695. Acesso em: 10 jan. 2020.

RIBEIRO, L. O nascimento da polícia moderna: uma análise dos programas de policiamento comunitário implementados na cidade do Rio de Janeiro (1983-2012). Análise Social, v. XLIV, n. 211, p. 272-309, 2014. 
RIBEIRO, L.; MONTANDON, A. M. A. Reformar a polícia ou reformar o seu discurso? Uma análise da chegada da filosofia de policiamento comunitário a uma organização policial militar brasileira. Revista Brasileira de Segurança Pública, v. 9, n. 1, p. 62-81, 2015.

RIBEIRO, L.; OLIVEIRA, V. N.; DINIZ, A. M. A. Los significados de "policía comunitaria" para la Policía Militar Brasileña". Estudos Sociológicos, v. XXXIV, n. 102, p. 603-638, 2016.

RICCIO, V.; RUEDIGER, M. A.; ROSS, S. D.; SKOGAN, W. G. Community policing in the Favelas of Rio de Janeiro. In: RICCIO, V.; SKOGAN, W. G. (Eds.). Police and Society in Brazil. 1 ed. Boca Raton: Routledge, 2017, p. 151-163.

ROUSSEL, A. Re/Presenting the Community: Power, Race, and Division in South LA's Community Policing Program. Tese (PhD em Criminologia, Lei e Sociedade) - Universidade da Califórnia, Irvine, 2013.

SILVA, G. T. da. T. Interfaces possíveis entre o Programa de Policiamento Comunitário e órgãos públicos e privados: estudo de caso da região do Jardim Ranieri. Dissertação (Doutorado em Ciências Policiais de Segurança e Ordem Pública) - Centro de Aperfeiçoamento e Estudos Superiores, São Paulo, 2006.

SOUSA, R. C. de; FEIRREIRA, M. D. M. Polícia Comunitária: Avanços e Retrocessos na Política de Segurança Pública Brasileira. Revista FSA, v. 1, n. 11, p. 220-244, 2017.

SOUZA, E. C. Sedimentação da Polícia Militar do Estado de São Paulo como referência em Doutrina de Polícia Comunitária para a América Latina e demais Estados brasileiros. Tese (Doutorado em Ciências Policiais de Segurança e Ordem Pública) - Centro de Altos Estudos de Segurança, São Paulo, 2019.

STEINBERG, J. Policing, state power, and the transition from apartheid to democracy: A new perspective. African Affairs, v. 113, n. 451, p. 173-191, 2014.

TAVARES DOS SANTOS, J. V.; TEIXEIRA, A. N.; MADEIRA, L. M.; SCHABBACH, L. M.; DURANTE, M. O.; PIMENTA, M. M.; FACHINETTO, R. F. Programas de Polícia Comunitária no Brasil: avaliação e propostas de Políticas Públicas de Segurança. In: FIGUEIREDO, I. S.; NEME, C.; LIMA, C. S. L. (Eds.). Políticas Públicas: análise e diagnósticos. Brasília: Ministério da Justiça/Secretaria Nacional de Segurança Pública, 2013.

UNIVERSIDADE FEDERAL DE MINAS GERAIS. Avaliação do Policiamento Comunitário da Polícia Militar de Minas Gerais em Belo Horizonte. Relatório de Pesquisa. Belo Horizonte: CRISP, 2009.
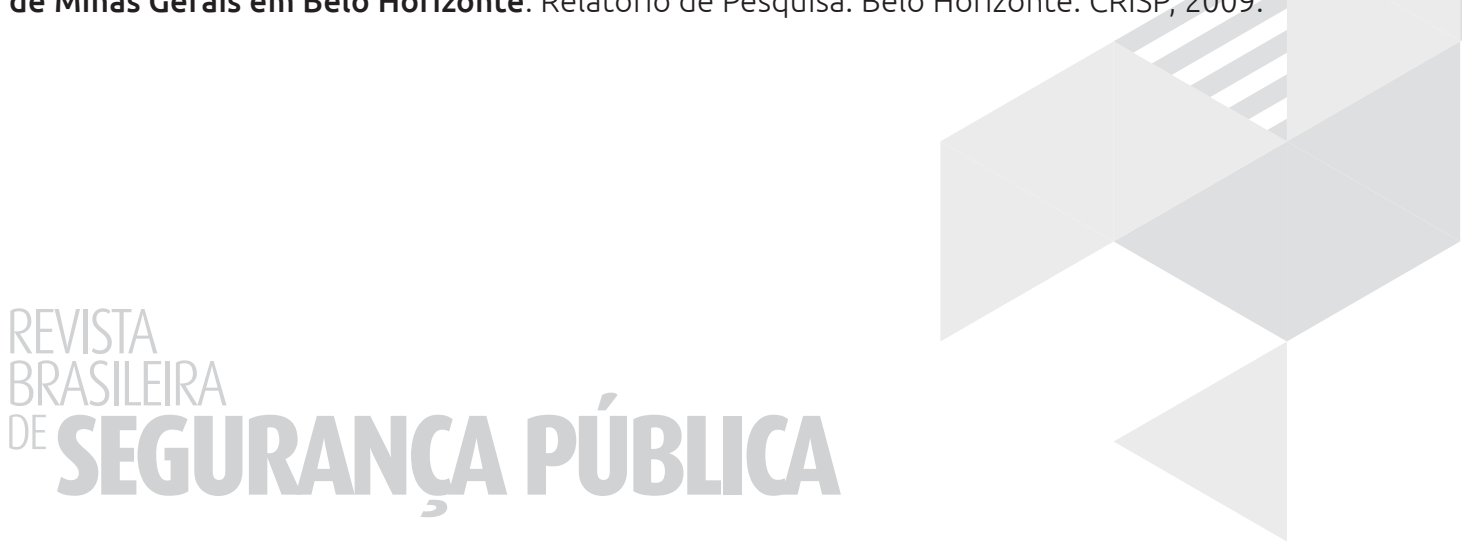